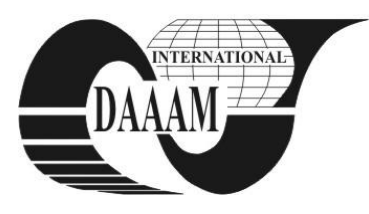

Annals of DAAAM for 2011 \& Proceedings of the 22nd International DAAAM Symposium, Volume 22, No. 1, ISSN 1726-9679 ISBN 978-3-901509-83-4, Editor B. Katalinic, Published by DAAAM International, Vienna, Austria, EU, 2011 Make Harmony between Technology and Nature, and Your Mind will Fly Free as a Bird Annals \& Proceedings of DAAAM International 2011

\title{
USING DOE TO IMPROVE SINTERED BASALT MECHANICAL PROPERTIES
}

\author{
PUGNA, A[drian] P[avel]; MOCAN, M[arian] L[iviu]; NEGRU STRAUTI, G[abriela] \& GIUCA, M[arilena] \\ G[eorgeta] O[livia]
}

\begin{abstract}
The paper presents an experimental study regarding the variation of compression resistance for sintered basalt. The experiments were performed according to Taguchi method and RSM method by using a L8 Taguchi standard experimental plan and a Draper-Lin small dimensions compositional experimental plan. For each experimental condition, 5 basalt sintered pieces were manufactured, which were tested to compression. There were sintered 25 pieces in each of two confirmation experiments analyzing the improvement in compression resistance by doping the basalt with $2 \% \mathrm{TiO}_{2}$. In order to verify the precision of designing the experiments based on the L8 orthogonal matrix, a full factorial simulation was also performed.
\end{abstract}

Key words: sintering, basalt, $\mathrm{TiO}_{2}$, Taguchi, $\mathrm{RSM}$

\section{INTRODUCTION}

Basalt sintering is a processing technique used to manufacture density-controlled parts with appreciable abrasive resistance and high resistance to chemical agents from basalt powder by applying thermal energy. An important application of basalt sintering is manufacturing components with high wearing resistance combined with high compression resistance in order to be used as brake disks and brake pads. The different stages of processing and corresponding variables for general sintering process are analyzed thoroughly by Kang (2005). Important contributions in analyzing the wear resistance of sintered basalt were presented by Cikara et al. (2010) and Gheorghies (2010). This study takes a step further, studying the possibilities of improving the compression resistance of sintered basalt through DOE by using $\mathrm{TiO}_{2}$ as dopant.

\section{SOLID STATE BASALT SINTERING}

Basalt, as raw material, in order to become a finished product through sintering process, undergoes through a series of operations such as: choosing the raw material, processing to obtain the powder form, forming, calcination and sintering. In this study were used natural basalt rocks, of volcanic origin, crystalline, compact, composed of a mixture of silicates, from Luncani, Timis county, Romania. In order to obtain basalt powder, the following operations were performed: washing, drying, sorting, crushing-sifting, disposal of metallic debris, milling and powder sifting. The basalt powder was mixed homogeneously with a binder consisting of a special glue, olein and water. Forming and pressing in die was performed with a newly designed pressure die for the purpose of this study (Pugna et al., 2010). Drying and calcination was achieved by placing compacted raw parts in boxes and calcinating them in a furnace, sintering and cooling of compacted basalt parts was performed in a sintering furnace. The components analysis of sintered basalt parts has been done through microanalysis technique with X-rays (EDAX). Surface images of sintered basalt parts were analyzed using a scanning electronic microscope (SEM).

\section{TAGUCHI AND RSM METHODS}

Taguchi methodology (Taguchi et al., 2000) uses for evaluating a product or process quality a synthetic measure of performance which takes in account simultaneously the mean and the variance (Signal-to-Noise ratio). For performing the experiments, there are usually used so called Taguchi standard matrices', for which are assigned controlled factors and interactions at different levels as inputs and a quality characteristic as output. There are performed experiments for each combinations of controlled factors, considering that the best one is that which produces the highest Signal-to-Noise ratio. One of the most popular experimental plans grouped under the Response Surface Method (when the cost of testing is high and number of experiments should be kept as small as possible) is the Draper-Lin plan. Draper-Lin plans - are small compositional plans on which the central portion of the plan consists of a fractional factorial plan with additional star points and a lower resolution than order V. The statistical model of Draper-Lin experimental plan expresses the response variable as a linear function of experimental factors, interactions between factors, terms of order 2 (quadratic) and an error term.

\subsection{Experimental results using Taguchi method}

The quality characteristic of basalt sintered parts was assigned as being, $\mathrm{Y}=$ Compression Resistance and the seven controlled factors, $\mathrm{A}=$ Composition; $\mathrm{B}=$ Calcination temperature; $\mathrm{D}=$ Cooling duration; $\mathrm{E}=$ Sintering temperature; $\mathrm{F}=$ Heating duration; $\mathrm{G}=$ Holding duration; $\mathrm{F}=$ Forming pressure). For each experimental condition 5 basalt sintered pieces were sintered, which were tested to compression. Therefore, it has been chosen a L8 Taguchi standard matrix, the factors levels for the 8 experimental conditions are presented in figure 1. The significant factors influences are presented in figure 2. In order to show the performance improvement the modification in normal distribution is presented as in figure 3. The improved $\mathrm{S} / \mathrm{N}$ ratio at optimal condition correspond to a reduction of standard deviation. To verify the precision of designing the experiments based on the L8 orthogonal matrix, a full factorial simulation $\left(2^{7}=128\right.$ experiments for full factorial experiment) was performed. The maximum value obtained from full factorial experiment combinations, can be regarded as exact solution which can be compared to the solution of the experiment based on L8.

Performance at optimal conditions can be compared with the exact solution. Relation (1) presents the equation obtained from simulating the full factorial experiment. The error using an L8 Taguchi standard matrix instead of a full factorial experiment is less than $1 \%$.

$$
Y=(10 A)^{1.97}+(0.1 B)^{1.55}+\frac{(10 C)^{0.61}(0.1 D)^{1.13}(10 E)^{1.53}}{(5 F)^{0.82}(0.1 G)^{1.95}}
$$




\begin{tabular}{l|llll} 
& \multicolumn{1}{|c}{ Factors } & \multicolumn{1}{|c}{ Level 1 } & \multicolumn{1}{c}{ Level 2 } \\
\hline 1 & Composition & $0 \% \mathrm{TiO}$ & $2 \% \mathrm{TiO} 2$ \\
\hline 2 & Calcination temp & $900 \mathrm{C}$ & $950 \mathrm{C}$ \\
\hline 3 & Cooling duration & $4 \mathrm{~h}$ & $5.5 \mathrm{~h}$ \\
\hline 4 & Sintering temp & $1000 \mathrm{C}$ & $1100 \mathrm{C}$ \\
\hline 5 & Heating duration & $8 \mathrm{~h}$ & $10 \mathrm{~h}$ \\
\hline 6 & Holding duration & $1 \mathrm{~h}$ & $1.5 \mathrm{~h}$ \\
\hline 7 & Forming pressure & $1500 \mathrm{daN} /$ & $2000 \mathrm{daN} / \mathrm{cm} 2$ \\
\hline
\end{tabular}

Fig. 1. Controlled factors levels

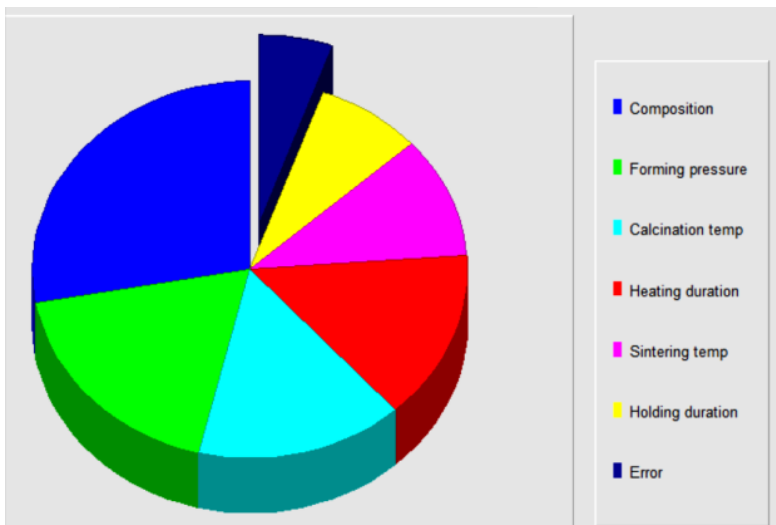

Fig. 2. Significant factor and interaction influences

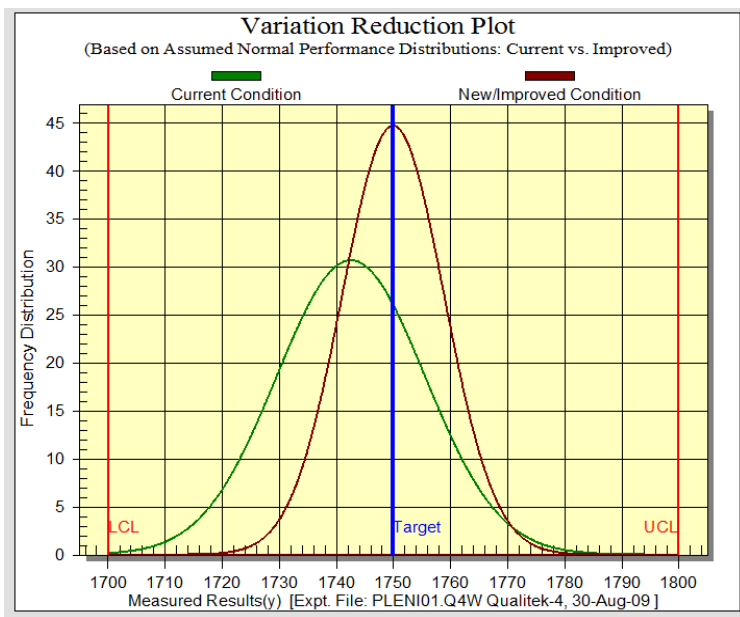

Fig. 3. Variation reduction plot

\subsection{Experimental results using RSM method}

It has been created a randomized and orthogonal DraperLin small compositional experimental plan, with which was studied the effect of 7 factors in 40 experiments in a single block (including two central points per block), with 4 degrees of freedom for error. In figure 4 is presented the standardized Pareto and in figure 5 is presented the Estimated Response Surface, the surface height representing the predicted values for Compression Resistance on an area determined by two factors the remaining five factors are kept at their average values.

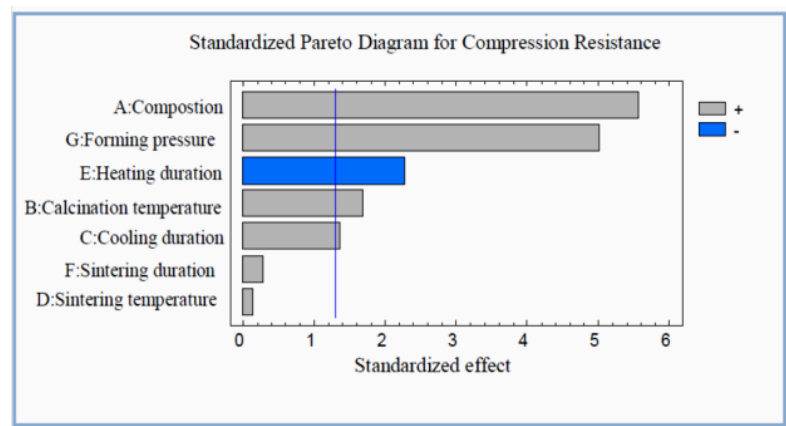

Fig. 4.Standardized Pareto Diagram for factors effect

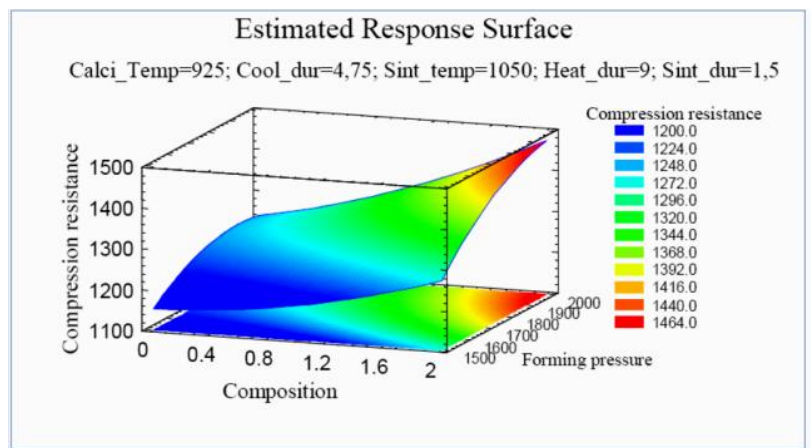

Fig. 3. Estimated response surface for compression resistance

\begin{tabular}{|c|l|l|}
\hline $\begin{array}{c}\text { Order of } \\
\text { importance }\end{array}$ & \multicolumn{1}{|c|}{ Taguchi $\mathrm{L}_{8}$} & \multicolumn{1}{|c|}{ Draper-Lin } \\
\hline 1 & Composition & Composition \\
\hline 2 & Forming pressure & Forming pressure \\
\hline 3 & Calcination temp. & Sintering temp. \\
\hline 4 & Heating duration & Sintering duration \\
\hline 5 & Sintering temp. & Cooling duration \\
\hline 6 & Sintering duration & Calcination temp. \\
\hline 7 & Cooling duration & Heating duration \\
\hline
\end{tabular}

Tab. 1. Comparison of factors order of importance

In table 1 are presented the factors order of importance for the Taguchi L8 and Draper-Lin experimental plans. One can see that in both cases the main two factors are Composition and Forming pressure.

\section{CONCLUSION}

Applying Taguchi and Draper-Lin experimental plans to sintered basalt parts identified the factors to be controlled. It was demonstrated that by using $2 \%$ of $\mathrm{TiO}_{2}$ as dopant, one of the major drawbacks of basalt sintered parts was partially eliminated and thus, the compression resistance of sintered basalt parts, was significantly improved. It was demonstrated also that by using an L8 Taguchi matrix the error that was made was insignificant by comparison with using a full factorial experiment. The main limitation is that the study doesn't take in account possible misalignments of brake disks and brake pads. Further researches will be focused mainly in reducing the brittleness of basalt sintered parts and introducing different angles of misalignments.

\section{REFERENCES}

Cikara, D; Todic. A \& Cikara-Anic, D (2010). Possibilities of Production of Wear Resistant Construction Elements by Processing of Serbian Basalt. FME Transactions. Vol. 38, No 4, 203-207, ISSN 1461-2091

Gheorghies, C. (2010). Sintered Basalt as a Promising Sustainable Material in Mechanical Engineering. Environmental Engineering and Management Journal. Vol.9, N. 8 (August 2010), 1133-1138, ISSN 1582-9596

Karamanov, A; Arrizza, L \& Ergul, S. (2009). Sintered material from alkaline basaltic tuffs. Journal of the European Ceramic Society 29 (2009), 595-601, ISSN 0955-2219

Kang, Suk-Joong. L. (2005). Sintering - Densification, Grain Growth, and Microstructure, Elsevier Ltd, ISBN 978-07506-6385-4, London

Pugna, A. P.; Negru Strauti, G. \& Mocan, M. L. (2010). Applying Taguchi Method to TiO2 Doped Sintered Basalt. Annals of the Oradea University. Fascicle of Management and Technological Engineering, Vol. IX (XIX), Nr1, 31513158, ISSN 1583 - 0691

Taguchi, G.; Chowdhury, S. \& Taguchi, S. (2000). Robust Engineering : Learn How to Boost Quality While Reducing Costs \& Time to Market, McGraw-Hill Professional, ISBN 978-0-07-134782-2, New York 